\title{
Art Education and Its Problems in Global Context
}

\author{
Ardipal \\ Music and Performance Education \\ FBS Universitas Negeri Padang \\ Padang, Indonesia \\ ardipalarly@ymail.com
}

\begin{abstract}
The history of art education in children and schools in Indonesia is characterized by changes and shifts in concepts (theories) and practices. Education of children at an early age, is actually not much of an issue. There is a slow shift towards art education with a more cognitive approach occurring under the influence of Reggio Emilia and socio-cultural theory of Vygotsky. However, progressive education and psycho-analytical theories and philosophies are still practiced and dominate the curriculum of early childhood art with an inherent dichotomy where on one hand still emphasizes processes rather than products, academic versus non-academic, integration of art separation, free versus play Adult direction, and playing versus work (Wright, 1991; Ritchie, 1999; Gunn, 2000). This ranking of art learning in Europe is inseparable from the issues of (1) different levels of decision-makers of the curriculum (central, local, local, school) Europe and the United States, (2) the purpose of art education (there are 14 destinations in Europe) and there are several options in Indonesia, (3) art curriculum organization (integrated or separate, integrated or not, Compulsory Art Subject or Optional) in Europe, Asia, and Indonesia, (4) The allocation of art teaching time is equally problematic globally because of the exclusion of art education, (5) it also results in teacher preparation, teacher quality, provision of teaching facilities, and evaluation systems. There are actually many myths, misconceptions, problems and issues in art education. But of all the issues and myths in art, the most important is the creativity in art, which needs to be developed in art education.
\end{abstract}

Keywords-Art Education issues; Europe; Asia; Indonesia, and Creativity

\section{INTRODUCTION}

As we know the world of education in Indonesia is generally influenced by various factors such as policy (politics, government, ministries, world organizations and so on). Similarly, Europe and America, the art education is also influenced by those factors as well as in Asia. This influence will result in the form of organization, the content of the curriculum, the policy of providing teachers of art educators. It means that art education is also influenced by many things beyond the interests of learning and art education itself. Especially related to the policy are issued by the government.

On the other hand, the policy of art education in Europe and America is different from Asia, as well as in Indonesia. Things like this can certainly be a question, what causes the existence of such of differences. If it is examined more deeply, theories and or the concept behind the policy, can be said that they are almost the same, if it cannot be said to be similar, namely the literature and concepts of educational thinkers from the West. Moreover, the increase of global communications results in the increasing of migration (migration between countries) and competition in various fields internationally.

Besides, the occurrence of technological improvements and the development of widespread economic knowledge also influence education policy. In the context of the population explosion and competition of this work, various countries treat them both positively and negatively. And many countries manage them to overcome unemployment and job competition in their country, one of the solutions is to strengthen the foundation in the field of education. In other words the education system can be seen as a means to prepare the young generation to play a role in this increasingly uncertain world.

Furthermore, the interest of international organizations shows a significant increase in recent years towards art education. It has led to the emergence of an important policy on this matter. UNESCO, for instance, has been a major force in the development of policy initiatives in education and culture in the last decade. For example in 1999, the Director General of UNESCO held a call to all stakeholders in the field of arts and culture education to ensure that art learning is given special attention and benefits in the education of every child, and school up to the final year of secondary school (UNESCO 1999) //www.unesco.org/ fileadmin/multimedia/HQ/CLT/CLT/pdf/Arts_Edu_RoadMap_en.pd).

This call was later responded in Europe and this was followed by a world conference in Lisbon to mark the culmination of a five-year international collaboration between UNESCO and its partner in art education. The conference underscores the need to establish the importance of arts education in all walks of life and this has been proven to be a boost for global research on the impact of art in education (Bamford 2006) and the UNESCO Road Map to improve Arts Education (UNESCO 2006). In this case UNESCO formulates as follows:

The Road Map aimed to provide advocacy and guidance for strengthening arts education. The document asserts that arts education helps to: uphold the human right to education and cultural participation; develop individual capabilities; improve the quality of education; and promote the expression of cultural diversity. (UNESCO, 2006)

Similar policy has taken place in Europe. In 1995, the Council of Europe launched a major project focusing on Culture, Creativity and youth. This is evident from the concern and enhancement of existing provision for art education in schools in 
European member countries as well as the involvement of professional artists and the availability of extra-curricular activities in schools in Europe. Improvements have also occurred in European art surveys and research and international deliberations.

In 2005, the Council of Europe launched the Framework Convention Convention Convention for the value of the community's cultural heritage (Council of Europe 2005), which identifies the needs of European countries to conserve cultural resources, promotes cultural identity, respects cultural diversity and fosters intercultural dialogue. Article 13 of the Framework Convention recognizes the importance of cultural heritage in art education and advocates the development of course relationships across the various fields of study. At the same time, three international bodies representing art educators of drama/theater, art and music together to form the international alliance of the world (International Society for Education through Art 2006). They are called on UNESCO to create an arts education center for the world agenda and for sustainable human development and social transformation.

In 2008 the Council of Europe published the White Paper for intercultural dialogue (Council of Europe 2008), which offers an intercultural approach in managing cultural diversity. It also includes identifying educational organizations (including museums, cultural heritage sites, kindergartens and schools) that are able to and has the potential to support intercultural exchanges, to learn and dialogue through art and cultural activities.

In March 2009, the European Parliament passed a resolution on Artistic Studies in the European Union (European Parliament 2009). Key recommendations include: art education must be compulsory at all levels of the school; teaching art should use the latest information and communication technology; teaching art history should involve meeting with artists and visits to cultural venues. In order to make progress on these issues, the resolution calls for greater oversight and coordination of arts education at the European level, including monitoring of the impact of artistic teaching and student competence in the European Union (Figel, Yan, 2009).

\section{Purposes of ART EduCATION}

According to Figel (2009) there are a small number of important questions about art education in Europe. From this question, it can be seen as the problems and important theme that can be compared and viewed as the difference with the development in Indonesian context. Of course from those similarities and differences, we can see that each has the weaknesses and and strengths. Some of the questions are discussed below.

Do all countries in Europe have the same curriculum weights of art? Where is the art placed in their national curriculum?

Almost all research on educational curriculum confirms that there is a hierarchy in the curriculum, ie where reading, writing and numeracy lessons are prioritized. And it is also seen that the priority of art education in European schools prioritizes mainly art and music, rather than other art (such as drama and dance). This is understandable because art and music represent two types of art that use human sight and hearing (Figel, Yan, 2009).

A survey of art education in Europe (Robinson 1999) takes place as part of the initiative of the Council for Culture, Creativity and Youth Europe. The study found that all national policy statements on education routinely emphasize the importance of cultural dimensions and the need to promote the artistic and creative abilities of young people. In practice, the status and provision of art in education is less prominent. The main disciplines taught are art and music. In most national systems, art is mandatory in primary education and for the first two or three years of secondary education.

Beyond this point, almost universally, art is optional. In all cases examined, art has a lower status than mathematics and other sciences. Even in some countries, there is an effort to reduce the existing provisions for art in the curriculum, instead supporting subjects considered more relevant to economic or academic success. Similar findings are also reported in international studies from (Sharp and Le Metais 2000; Taggart et al. 2004).

The two main approaches to framing the art in the national documents of European countries, which can be identified: (1) are generic art domains (also called 'integrated regions') or separate subjects. One concern about subject-based approaches is where drama and dance, which are often included in other fields of study, such as sports education. In particular, it is acknowledged that it may be difficult to promote the expressive quality of dance within the subject area focused on physical exercise and exercise. (2) Taggart et al. (2004) found that art and music lessons were a mandatory part of the study in all 21 European countries surveyed. About half of the countries/countries surveyed in Europe, where students are asked to study one or more disciplines of art until the age of 16 years. Other countries require that their pupils study art until the age of 14 , or follow arts subjects as elective or voluntary subjects, especially older students.

The relatively low status given to art subjects is reflected in the relative lack of attention, assessment and monitoring of standards in art teaching in Europe (Bamford 2006; Taggart et al. 2004). The results also highlighted and worried about the formal allocation of time for art education, as well as the time provided in schools, which is generally not sufficient space for presentation of a broad and balanced artistic curriculum (Robinson 1999; Sharp and Le Metais 2000; Taggart et al 2004.). Lack of time, space and resources have been identified as key factors inhibiting the success of art education (Bamford, 2006). 
What is the purpose of art education? Have all goals been given equal weight?

The existence of artistic pressures to meet various goals, in addition to teaching about art, yet the education system is increasingly recognizing the importance of developing children's creativity and contributing to cultural education, but it is not yet understood how actual art is expected to contribute well as individual subjects or by working with other curriculum areas. Taggart et al. (2004) found that almost all of 21 countries in Europe in their international studies have the same goals for the art curriculum. It also includes how to: develop artistic skills, knowledge and understanding, and engagement with various art forms; increased understanding of culture; sharing art experiences; and differentiate consumers of art and contributors.

In addition to artistic results, there are also personal and social character outcomes such as trust, self-esteem, individual expression, teamwork, intercultural understanding and the expected cultural participation of art education in most countries. In particular, attention to the aspect of creativity has to do with aspects of innovation and cultural education that is in relation to individual identity and intercultural understanding, so it clearly has something to do with the purpose of art education in general. This raises questions about the ability of the art curriculum to meet such diverse and broad objectives.

The objective analysis of the art and curriculum of cultural education is generally based on international studies, namely on the curricular objectives of art and cultural education (Sharp and Le Metais 2000). Nevertheless, there is a new category added in this regard in order to better reflect the contents of the art and cultural education curriculum in the European countries concerned). Among the goals are as follows:

1. knowledge and understanding of artistic skills

2. critical appreciation (esthetic appraisal)

3. cultural heritage (national identity, local culture)

4. cultural diversity (European identity/world consciousness)

5. individual expression/self identity/self-development

6. creativity (imagination, problem solving, taking risks)

7. social skills/working groups/socialization/cooperation

8. communication skills

9. Pleasure/Pleasure/Satisfaction/Happiness

10. the variety and diversity of art; engage with various forms of art/media

11. performances/presentation/performances (sharing artistic work among friends alone)

12. environmental awareness/conservation/sustainability/ecology

13. confidence/self-esteem

14. learn art and lifetime/interesting matter

15. Identify potential art (aptitude/talent)

The results of the study (Figel 2009) show that the first six of art learning objectives referred to above are listed in almost all art and cultural education curricula in Europe. That is the purpose of art learning is quite firmly connected with the purpose of general art education. All curriculums refer to 'artistic skills, knowledge and understanding. Of the six objectives, at least five EU states said creativity is not included in their art learning objectives.

Artistic skills, namely knowledge and understanding, in general, where skills form the basis of 'artistic language' (such as understanding color, lines and shapes in art or, in music, listening and performing skills using instruments). The development of artistic skills tends to include learning different artistic styles and genres. In that case, some countries refer to the repertoire of certain works, especially for music and drama. An understanding of the artistic aspect usually tends to focus on artistic concepts, such as understanding the characteristics of different ways of artistic expression or art expressions related to the relationship between artist and environment, physical, work, and sociocultural.

Critical appreciation is among the six most commonly called/used goals. It relates to raising students awareness of important features of a work or achievement and for developing their capacity for critical judgment in evaluating their own work or others.

Cultural heritage. Almost all countries attach the importance to the understanding of cultural heritage. In some cases, goals are linked to the creation of cultural identity: learning cultural forms seeks to develop self-understanding as a citizen of a country or member of a cultural group. Understanding cultural heritage is promoted through contact with artwork, as well as through learning of the characteristics of the artwork produced in the periods of the history of different individual states and different particular artists.

Understanding cultural diversity, aims common to most curriculum goals and learning art and culture. The promotion of cultural diversity through art also seeks to raise awareness of cultural heritage and modern genres specific to different countries and cultural groups (sometimes with specific reference to European culture).

The development of individual expression and the development of creativity are two other very broad purposes, although the latter is called very little in European countries. The development of individual expressions of children by means of art is closely related to their emotional expression. Usually connected with all forms of art but especially with fine art gets more attention. Creativity development can be defined as the development of the capacity of individuals to participate in imaginative activities, 
products to be marked by originality and value (Robinson 1999). Although its relation to the development of individual expressions is clear, the development of creativity is quite different and is regarded as a separate type of artistic purpose.

Social skills. The most commonly mentioned goal is 'social skills development': it is identified by 26 curricula of countries in Europe. Generally, that goal is more specifically related to performing arts, in certain dramas.

Pride. The most cited is self-esteem development or self esteem 'by participating in art activities: only 15 curriculum (EU countries) call it. The development of 'pleasure/satisfaction' and 'communication skills' is the goal contained in almost the same number of curricula (each in 23 and 24, EU countries). The first is common to all forms of art, while the second development through art is primarily related to performing arts (music, drama and dance) as well as media art.

Social Awareness, 'raising students' on their environmental awareness' is a goal found in 20 EU art curriculums. That is achieving goals that require appreciation of the physical environment, an understanding of the origin of materials used in art and the responsibility for ecological conservation.

Art Exhibition. Among the objectives of learning/outcomes that are firmly connected with a fairly specific art, the exposure of various experiences and various means of artistic expression and skills in performing or presenting a work are the goals most commonly referred to in the curriculum (22) and in general all forms of art.

Talent Development. In the same category, the two most frequently mentioned goals are 'developing lifelong interest in art'; in other words, encouraging students to participate in extracurricular arts activities and maintaining that interest throughout their lives ( 15 countries refer to it); and especially 'identifying potential/talent potential', defined by only 6 curriculums in the EU.

In addition to the learning objectives identified as part of the art and the cultural curriculum, there is also a learning objective in the overall curriculum that can be related to art and cultural education. On the one hand, some curricula refer to the specific objective of encouraging cross-curricular links between art subjects and other subjects.

On the other hand, while not necessarily mentioning cross-curricular links, in some countries there is an element of the whole curriculum that deals with creativity as well as art and cultural education. It is also a potential indicator of cross-curricular arts and cultural education. Elements such as the entire curriculum include references to creativity, cultural heritage, cultural diversity, the development of individual expressions and identities, artistic experiences and means of expression, social skills, group work and interests to participate in cultural activities.

How are teachers prepared to teach art? How does the education system monitor the teaching standards in art in the EU?

Bamford (2006) points out that many educational systems rely on generalist teachers to teach art subjects, especially for young people. Teaching art to a high standard for general teachers is quite challenging, so it is not surprising to find that there is a major art teacher and a lack of confidence particularly in teaching art (Taggart et al., 2004). It will therefore increase the need to consider both the teacher's initial preparation to teach art subjects and arrangements for development for sustainable professionals, to enable art teachers to update their knowledge and develop their skills.

Arrangements for the quality of monitoring teaching in art have received little attention in recent research studies, although there are often reference concerns about the variability of standards and the need to provide high quality learning experiences in schools (Bamford 2006; Robinson 1999; Sharp and Le Metais 2000; Taggart et al 2004).

Robinson (1999) highlights the structural problems that hinder the development of binding art education in public schools. The government has responsibility for art and education that is often shared between two or more departments separated from education and culture, and sometimes youth and sports, which can make it difficult to achieve a shared understanding of the art education needs and priorities in the EU.

\section{Extra-curricular opportunities in art and cultural learning, but how?}

Children's access to art and cultural experience such as museum visits in Europe has become important, especially since schools have the potential to improve inequality by providing access to cultural resources for children from disadvantaged backgrounds (see Robinson 1999; Sharp and Le Metais 2000). Things like this are rare, and arguably can not be done in Indonesia, because the art museums only exist in the center of government like Jakarta.

Are professional artists involved in art education, and if so, how?

The involvement of professional artists in art education has been recommended in several studies (Bamford 2006; Robinson 1999; Sharp and Le Metais 2000). The main reasons given for this are: to improve the quality of teaching and art learning, encourage greater creativity, improve teachers' skills and confidence, and provide access to a wider range of cultural resources. Bamford (2006) identifies the relationship between the quality of art education and the involvement of professional artists: 'the quality of art education tends to be characterized by a strong partnership between school and outside art and community organizations. For now, we know relatively little about the nature and extent of the national system to enable such partnerships.

How should the art curriculum respond to new technological developments, new media?

Research studies (Bamford 2006; Sharp and Le Metais 2000; Taggart et al. 2004) have highlighted the pressures for curriculum development in art; 1st century to include new media studies (including film, photography and digital art) that enable 
students to use technology, Information and Communication (ICT) as part of the creative process. There are also emerging tre nds for cross-curricular work, involving art and other lessons (non-arts) where several fields of study work together on a creative and/or cultural theme. The development of all this will certainly provide new demands on teachers and schools who need direction from leaders and support at the policy level.

\section{THE Focus of ART EdUCATION IN Asia: GENERAL EdUCATION AND CULTURE}

The view of some artists in Asia is somewhat different from that in Europe (Maira, Shakti, 2006: Kapila Vatsyayan (1996)) One of the benefits of art education education in Asia is the art as an instrument in general education. This is one of the goals of art in education common, an approach where art is used as a tool to educate students through certain subjects.Arts of Arts education in Asia agree that learning through their own culture is important, and how that culture has changed and how it relates to other cultures. With the art learning system so students are better able to build their own personal sense of identity, and increase their self-confidence and ownership of their own culture.Because of the importance of art in improving the quality of education, and in fostering social ties, peace and prosperity, therefore there are efforts around the world to combine art with all education systems.

Furthermore, many believe that the notion of art in Asia, and in the Asia-Pacific region in general, is not very understand the "art" as understood in the sense of Western art, where in the West the art is a product of high social class and delivered in formal institutions built like a museum, concert hall, and others. Art for Asians is part of a living tradition, rooted in the local community, and is often held and consumed by the poor class.

Traditionally, art in most Asian and Pacific cultures - if not all - is an integral part of their own lives: where the related forms and functions of art are not contextualized. For example, traditionally, art is an ordinary object in everyday life that is often not only functional but beautiful and meaningful.

Art in the Asia-Pacific region has traditionally been an integral part of their daily lives; therefore in the Asia-Pacific region art is the vehicle of knowledge and learning methods of all subjects. In addition, art teachers in the Asia-Pacific region can traditionally be found in the community. Art education is based on the tradition of internship or most of it is non-formal. In recent years in most, if not all, Asia-Pacific societies, has had a shared experience of internalization of Western-style art and education structures.

In Asia-Pacific countries, as in most contemporary societies, artistic activity has been severely limited to a small part of human effort. For example, art activities in schools are only a very narrow activity of class activities, usually consisting of art parts such as drawing and painting. The creation of art as if it is separate and separate from life experience and art has been separated from other disciplines and has no major role in education. It should be a knowledgeable community in Asia Pacific, reexamine the education system in order to be a way and have the means to adapt to local art and culture. The process of adaptation implies rethinking about roles and utilizing art in education.

In addition, Western ways and approaches to art instruction are also not wrong, because it usually focuses on teaching art history, aesthetics and learning artistic skills so that students are able to reproduce the art form in a competent way. However, frequent irregularities, where Western methods should be in place, also allow the Asia-Pacific community to fully withdraw their knowledge, skills, cultural wealth or contribute to preserving and preserving the art and cultural traditions of their own region.

The conclusion of the 2004 Asian regional experts symposium, with the main topic "Measuring the Impact of Arts in Education", organized by the UNESCO Regional Office of Advisor for Culture in Asia and the Pacific in collaboration with the Hong Kong Institute of Contemporary Culture (HKICC), and took place in Hong Kong SAR , China, 9-11 January 2004. Summarizes 3 main topics: (1) That Art Contributes To Student Intellectual and Social Development, (2) Improves Quality of Education, (3) That art can enhance Creativity and contribute to Security of Cultural Diversity.

According to the view of art experts in Asia believe that the diversity of art in intercultural cultures in Asia actually contains the philosophy of their common life. In Asia, traditionally the purpose of art is not in the making of 'art' in the present sense; therefore it differs from the arts in Asia, where art is integrated with the function of life (Shakti Maira, 2005). For the Asian community, art is the bridge between the natural world, human and divine; and as a tool for meditating, understanding and transformative experience. Creation and learning are interrelated: art and knowledge are almost identical. Art is functional but also beautiful and meaningful. Generally art in Asia has a purpose, both to channel and transform their life value; channeling their skills and values and thereby altering one's sense of self and identity, supporting social cohesion. This is the ancient basis for a "new" vision of art in education: learning through art.

The dichotomy of the Western way and the Eastern way is seen from the dichotomy between individual values (expression) and social values. Western influence on art education in the classroom usually consists of activities such as drawing, painting a particular object. The primary value of the creation of art in children is seen as the development of the value of individual selfexpression and there has been a reduction of communicative and social values.

Hence to a certain extent, all Asian societies are trapped between the (1) "modern" model of art education on the one hand and (2) indigenous knowledge and more holistic and integrated art traditions on the other - with different perceptions of the place art and culture in their life and education. The continuing decline of art, in education, is due to the emphasis of art and technology of modern society, which streamlines the artistic activities of the school curriculum. 
In addition, most Asian societies always think that education is a means to improve economic and social status. Educators, parents and children want to go to school and focus on getting their children to go to college, then getting into a job and a certain profession, which is better paid. Therefore every major flow of the art education in schools should be related to twin issues, namely how the connection of the value of art to the needs of society, and the use of art in schools in line with the method of art education and eventually used for development curriculum.

There is a need to direct education in a sustainable and effective manner to create awareness and understanding in Asian societies toward the skills children need eg engineering, computer systems design, advanced medical science and nuclear science. Then the ability to think like thinking space, lateral thinking, creative problem solving, pattern recognition, cognition, concentration, perception, communication and teamwork, are unique and this can be developed and maintained through art education. There is a consensus that art education needs to be made more relevant to the daily life and local cultural practices of the students, and brings an art perspective and moves away from ineffective and outdated art learning methods.

According to Vibeke Jensen and George A. Attig, the current quality of education in many rural schools in Asia is generally low and the situations often faced by teachers and students in schools are characterized by the following factors: (1) lack of teacher interest and enthusiasm, (2) ineffective teaching-learning methods, (3) lack of community participation and limited resources in teaching and learning.

The integration of art in education can be seen as a means to overcome these difficulties and improve the quality of basic education. "Art in education" or the role of art in education can be seen in two ways, namely, "art education" and the approach to art education is an award in which art is taught as part of the curriculum. Students should have an "art" class, and the teachinglearning process focuses on developing their artistic skills and appreciation of "art," usually as a valued part of their own culture.

On the other hand art in educational approaches, using art as a means to improve the quality of education, through: (1) improving teacher/student motivation; (2) enhancing teaching and learning processes; (3) encouraging active learning techniques; and increasing community participation. In addition, the integration of art in education is believed to have a positive impact on such things as student self-esteem, creativity, problem-solving skills and the ability to work in teams.

To support his conception, Jensen and Attig (2005) refer to Gardner's theory. According to him, the art of educational approach refers to the theory developed by Dr. Howard Gardner: the "double intelligence" theory (Gardner 1983). There are different modes of learning and intelligence and people tend to be "intelligent" in one other mode. Gardner also theorizes that when children learn they use various modes of intelligence. Gardner identifies eight types of intelligence: linguistics (words); logical-mathematical (number/reasoning); spatial (image); kinesthetic-body (body); music/rhythm (music); interpersonal (people); intrapersonal (self) and naturalist (nature).

Through the dedication and use of art in the educational approach, many school difficulties can be overcome. First, teachers can improve the resources available in their schools, develop their teaching skills and teaching methods, and have involved communities in school life and learning of children - thereby improving children's learning abilities and the overall quality of their education school. Achievements may be replicated elsewhere if the teacher is given the proper training.

Teacher training in the arts in educational approach will enable teachers to make changes and overcome difficulties and will also enhance teachers' professional pride and confidence. As part of this training, teachers should be provided with a "toolkit" consisting of practical suggestions on how they can use the art, cheap materials, and resources available to make teaching learning relevant, engaging, and fun. There is an urgent need for such toolkits to be developed.

Training in the arts in educational approach will also enable teachers to increase community participation in schools. Teachers will learn art that teachers can use to bring schools and communities together. By inviting community elders (who can tell folk tales and stories) and traditional craftsmen to share their knowledge and abilities with their students, teachers can put pressure on human "idea banks" and provide students with interesting and relevant information and skills. Such an approach would have the added benefit of raising students' awareness of the value of local customs, beliefs and skills, and encouraging the preservation of traditional knowledge and crafts; thus contributing to the safeguarding of cultural diversity.

\section{THE IMPORTANCE OF CREATIVITY}

According to Janis Boyd, art education is needed to cultivate a widespread creative life that offsets the power of mass production and mass consumption in today's highly materialistic society. Art education is needed as a boost for change, challenging old perspectives from a new perspective, or offering genuine interpretations of familiar ideas. There is criticism; generally paid work is seen as a goal by society, while artistic activity is not considered to have a real purpose.

Creativity turns out to be a greater focus on cognition, not just on the development of feelings (Eisner, 2002: Gardner, 1982). This understanding will be more balanced if there is a view that comes from the field of art education and subsequent creativity that is reflected in various subjects and discussed in different versions of the national curriculum. According to Fleming, Mike (2010), creativity is often regarded as an individual mental process aimed at the production of something new. In the context of art education things like this can be seen and have (and still have) the consequences that are misleading. If this is used then it means that there is no criterion for the outcome of consideration and anything that is considered 'creative' can be appreciated or valuable. 
All educational experts would agree that when children make art, they are actually exploring, discovering, and thinking. Art encourages the originality of the child and uniquely expresses the unpredictability (predicted) as follows, ".... in the process of art creation, there is a distinctive characteristic that distinguishes between art, craft and design. Art artists such as poets (literature, lyricist), and sometimes painting, artists do not know what he will say until he sets the phrase "He can not reveal previously finished art work such as: the poet can not say any words before the poem is finished."

Furthermore, as we know Western art learned in education is actually "high art", such as classical music, and ballet dance. The difference between high and low art is initially easy to recognize but difficult to maintain and Fisher (2001) says, it is relatively easy to establish Shakespeare and classical music as high art for one category and pop music and other soap operas as "low art", but these criteria and differences are very challenging.

\section{EPILOGUe}

Until now there are still questions, if problems in pedagogy have been overcome. Can the various arts and cultures be integrated to benefit even when it is assumed that most teachers do not know the true meaning of 'integration'?

Is the (different) material art study appropriate to the national curriculum objectives? The determination of the type of art learned can ultimately fall on a school-based decision, but is there a parallel between the five forms of art? Art Nature shows that they can not converge into measurable results without making them a series of generic 'curved' results derived from their original source of art.

Thus, art education is an important thing in the social, cultural and economic context. The benefits of Art have to be fully realized. Art and education can be seen in three contexts - (1) as a means to build an appreciative and informed audience, (2) as a means to develop professional art practitioners and (3) to prepare students to engage in cultural and creative life.

\section{References}

Acland, R. (1967) A move to the integrated curriculum. Themes in Education. No. 7. Great Britain: University of Exeter, Institute of Education.

Bamford, A., 2009. An Introduction to Arts and Cultural Education Evaluation. Unpublished paper commissioned by Creativity, Culture and Education (CCE).

Beane, J.A. (1995) Curriculum integration and the disciplines of knowledge. Phi Delta Kappan. 76 (8). pp. 616-622.

Bernstein, B. (1967) Open schools, open society, New Society. 14 September.

Bernstein, B. (1971) On the classification and framing of educational knowledge. In Young, M.F.D. (Ed.) Knowledge and Control. London: Routledge and Kegan Paul.

Blum. A. (1973) Towards a rationale for integrated Science teaching. In Richmond, P. (Ed.)

New Trends in Integrated Science Teaching, Vol. II. Paris: Unesco.

Bolam, D. W. (1970) Integrating the Curriculum- a case study in Humanities. Paedagogic Europaea 6, pp.157-171.

Boyd, J. (1989) Integration - A Process Structure in Visual Arts. (Unpublished Masters Thesis), Armidale: University of New England.

Boyd, J. (1994) in Edwards, J. (Ed.) Thinking: International Interdisciplinary Perspectives.

Brophy, J. and Alleman, J. (1997) A caveat: Curriculum integration isn't always a good idea. Educational Leadership. Theme: Integrating the Curriculum. p. 66.

Brown, N. (1995) in The Report by the Senate Environment, Recreation, Communications and the Arts References Committee: Arts Education (October 1995). p.185. Parliament of the Commonwealth of Australia.

Calouste Gulbenkian Foundation Report: The Arts in Schools: Principles, Practice and Provision. London: 1982.

Collier, S. and Nolan, K. (1996) Elementary Teachers' Perceptions of Integration. Paper presented at the Annual Meeting of the Mid-South Educational Research Association. Tuscaloosa, AL, November 7, 1996.

Creative Nation - Commonwealth Cultural Policy, October. 1994. p.85. Parliament of the Commonwealth of Australia

Deverell, J. (1995) in The Report by the Senate Environment, Recreation, Communications and the Arts References Committee: Arts Education (October 1995, p.18). Parliament of the Commonwealth of Australia.

Education Queensland P-10 Arts Framework (1990). Brisbane: Goprint.

Education Queensland Submission in The Report by the Senate Environment, Recreation, Communications and the Arts References Committee: Arts Education (October 1995, p.1368). Parliament of the Commonwealth of Australia.

Eisner, E. (1981) The Role of Arts - Cognition and Curriculum. Phi Delta Kappan, September. 1981.

Figel. http://eacea.ec.europa.eu/education/eurydice/documents/thematic_reports/113EN.pdf

Gardner, H. (1982) Art, Mind \& Brain: A Cognitive Approach to Creativity. U.S.A. Basic Books.

Gwynn, J.M. \& Chase, J.B. (1969) Curriculum Principles and Social Trends. New York: Macmillan.

Hirst, P.H. and Peters, R. S. (1973) The Logic of Education. London: Routledge and Kegan Paul.

Hughes, M. (1991) Curriculum integration in the primary grades: A framework for excellence. Alexandria. VA. Association for Supervision and Curriculum Development.

Lawton, D. (1975) Class, Culture and the Curriculum. London: Routledge and Kegan Paul.

Ministerial Council on Employment, Education, Training and Youth Affairs. The National Report on Schooling in Australia 1993 , Curriculum Corporation 1993.

Moulez, G. J. (1973) Psychology of Effective Teaching. New York: Holt, Rhinehart and Winston. Morris, J. Ut. (1970) Towards a balanced curriculum. Trends in Education, 18, pp.10-17.

Robinson, K., 1999. Culture, Creativity and the Young: Developing Public Policy. Cultural Policies Research and Development Unit Policy Note No. 2. Strasbourg: Council of Europe.

Shakti Maira (2005) Simposium tentang Seni dalam Pendidikan Asia, Transmisi dan Transformasi: Belajar Melalui Seni di Asia, adalah upaya bersama antara Kantor Regional Advisor UNESCO untuk Kebudayaan di Asia dan Pasifik, dan India International Center - Asia Project (IIC - Asia Project).

Taggart, G., Whitby, K. \& Sharp, C., 2004. Curriculum and Progression in the Arts: An International Study. Final report (International Review of Curriculum and Assessment Frameworks Project). London: Qualifications and Curriculum Authority.

UNESCO (United Nations Educational, Scientific and Cultural Organization): Road Map for Arts Education, The World Conference on Arts Education: Building Creative Capacities for the 21st Century Lisbon, 6-9 March 2006, p. 2. 